\title{
No association of income inequality with adult mortality within New Zealand: a multi-level study of 1.4 million 25-64 year olds
}

\section{T Blakely, J Atkinson, D O'Dea}

See end of article for authors' affiliations

Correspondence: Dr T Blakely, Department of Public Health, Wellington School of Medicine, University of Otago,

PO Box 7343, Wellington, New Zealand; tblakely@wnmeds.ac.nz

Accepted for publication 23 August 2002

\begin{abstract}
Study objective: To determine the association of regional income inequality within New Zealand with mortality among 25-64 year olds.

Design: Individual census and mortality records were linked over the 1991-94 period. Income inequality (Gini coefficients) and average household income variables were calculated for 35 regions. "Individual level" variables were sex, age, ethnicity, household income, rurality, and small area socioeconomic deprivation. Logistic regression was used for the analyses. Sensitivity analyses for the level of regional aggregation were conducted.

Participants: 1.4 million New Zealand census respondents aged 25-64 years followed up for mortality for three years.

Main results: Controlling for age, ethnicity, rurality, household income, and regional mean income, there was no association of income inequality with all cause mortality for either men $(O R=1.007$ for a 0.01 increase in the Gini, $95 \%$ confidence intervals 0.989 to 1.024 ) or women (OR=1.004, 0.983 to 1.026). By cause of death (cancer, cardiovascular disease, unintentional injury, and suicide) there was some suggestion of a positive association for female unintentional injury (OR=1.068, 0.952 to 1.198 ) and suicide $(O R=1.087,0.957$ to 1.234$)$ but the $95 \%$ confidence intervals all included 1.0. Failure to control for ethnicity at the individual level resulted in some association of increasing regional income inequality with increasing mortality risk. Using fewer $(n=14)$ or more $(n=73)$ regional divisions did not substantially change the findings.

Conclusion: There is no convincing evidence of an association of income inequality within New Zealand with adult mortality. Previous ecological analyses within New Zealand suggesting an association of income inequality with mortality were confounded by ethnicity at the individual level. However, this study does not refute the possibility that income inequality at the national level affects health.
\end{abstract}

$\mathrm{T}$ he association of income inequality with health is contentious. Between countries, increasing infant mortality has been consistently associated with increasing income inequality. ${ }^{1-3}$ However, the landmark paper by Wilkinson ${ }^{4}$ that reported an association of income inequality with life expectancy among OECD countries has been strongly contested. ${ }^{3}$ Within the United States the association has been demonstrated with mortality in ecological studies at the state, ${ }^{56}$ metropolitan area, ${ }^{7}$ and county ${ }^{8}$ levels. Multi-level studies that control for individual level demographic factors and income find an association of state level income inequality with self rated health ${ }^{9}{ }^{10}$ but only a modest or equivocal association with mortality. ${ }^{112}$ At lower levels of geographical aggregation in the US multi-level studies have produced both positive ${ }^{13}$ and (essentially) null findings ${ }^{14}$ for self rated health, and null findings for mortality. ${ }^{15}$ Within other countries the evidence is similarly mixed: ecological studies in England ${ }^{16}$ and New Zealand $^{17}$ have found positive associations, but not in Canada. ${ }^{18}$ Multi-level studies in Japan ${ }^{19}$ and Denmark ${ }^{20}$ have not found reliable evidence of an association.

Should an ecological association of income inequality with health exist over and above the well known association of personal socioeconomic position with health, three alternative pathways of action have been proposed: (1) variations in a person's access to life opportunities and material resources (for example, health care, education; sometimes referred to as a "neomaterial" mechanism); (2) resultant variation in social cohesion, whereby mutual support and cooperation (in contrast with social division) secure better health outcomes; and (3) possible direct psychosocial processes related to rela- tive perceptions of position on the socioeconomic hierarchy. ${ }^{21}$ These different mechanisms invite additional and varying policy responses that focus on societal structure through to personal coping strategies. ${ }^{22}$ It is also likely that these mechanisms may vary in importance depending on the level of analysis. For example, mechanism (1) above is implausible at regional levels where there is no variation in welfare and other social service provision. Assuming an ecological relation does exist, though, simply reducing income inequality should improve health status regardless of which mechanism is acting. Furthermore, should no ecological association exist, the curvilinear association of income with health at the individual level ${ }^{23}$ means that reducing income inequalities may still improve health status.

In this paper we use a large record linkage study of New Zealand census and mortality records to test the income inequality hypothesis at various levels of geographical aggregation within New Zealand using a multi-level study design.

\section{METHODS}

Record linkage of census and mortality records

This paper uses a cohort study of all New Zealanders formed by record linkage of 1991 census records to 1991-94 mortality records. ${ }^{24}{ }^{25}$ A total of 1654314 people aged 25-64 years completed the 1991 census. Of the 19128 mortality records for people aged 25-64 years on census night and dying within three years after the 1991 census, 14322 (74.9\%) were linked back to a census record. 


\section{Individual level variables}

Individual level variables from the 1991 census included sex, age, ethnicity (Maori (indigenous population), Pacific, nonMaori non-Pacific), equivalised household income and rurality. We calculated the equivalised household income by first assigning to each census income category the mean income for the equivalent category from the 1991 New Zealand Household Economic Survey, then totalled the income of all adults usually resident in the household. Equivalisation was achieved by dividing the total household income by the square root of the number of people in the household. For example, a total household income of $\$ 50000$ for four people became an equivalised household income of $\$ 25000$. (No household income could be calculated if a usually resident adult was not home on census night, or one or more adults did not specify their income).

\section{Regional level variables}

Three different sets of regions were analysed: 14 regional councils, 35 health funding authority sub-regions (hereafter called sub-regions), and 73 territorial authorities. Sub-regions are aggregations of territorial authorities that approximate hospital catchment areas. Sub-regions were used for most analyses as: they have been used previously (with slight modification) in an ecological study of the association of income inequality with mortality ${ }^{17}$; the variation in population size between territorial authorities was too large (range 760 to 315668 persons (all ages), 25th centile of 14433 and 75th centile of 51 607); and there were only 14 regional councils. The sub-regions ranged in population size from 13280 (North Canterbury) to 315668 (Central Auckland), with a median of 74587,25 th centile of 41958 , and 75th centile of 131537 . For each of the regions, the average household income and Gini coefficient (measure of income inequality) were calculated using 1991 census household income data. At the sub-region level, the 25th, 50th, and 75th centiles of the Gini coefficient were $0.334,0.338$, and $0.35 \mathrm{l}$, and of the average household income were \$20 019, \$21 545, and \$23842.

\section{Analyses}

The analyses in this paper excluded deaths in the first six months to reduce the possibility of health selection effects and were restricted to those census records with complete data, resulting in a sample size of 1.4 million 25-64 year olds (688 857 men and 702 261women; $84.1 \%$ of all 25-64 year old census respondents). Most exclusions were attributable to missing household income data, and extensive sensitivity analyses published elsewhere suggested little resultant selection bias. ${ }^{26}$ Analyses were not conducted for children due to lower statistical power and were not conducted for 65 year olds and over due to convergence of household incomes. Four causes of death were also examined (cancer, cardiovascular, unintentional injury, and suicide) on the basis that any mechanism of action for income inequality would probably vary by cause of death (for example, social cohesion and fragmentation might be more important for suicide). There is also the possibility of varying time lags by cause of death. All individual level variables were treated as categorical variables in the analyses, but the two regional variables were analysed both as quartile and continuous variables. For models including the Gini as a continuous variable, we report the odds ratio for a 0.01 increase in the Gini. Analyses were conducted in SAS v8.0 using logistic regression on site at Statistics New Zealand under strict privacy requirements (see SNZ Security Statement). Regression models used exact data, but all frequency output presented in tables in this paper are random rounded to a near multiple of three as per SNZ protocol. As the outcome of death among 25-64 year olds followed up for three years is relatively rare, the odds ratio is a good approximation of the risk ratio.
Three sensitivity analyses about the all cause mortality results were conducted. Firstly, the main model at the sub-regional level was run at the territorial authority and regional council levels. Secondly, we adjusted for variation in the record linkage success by the regional categories of income inequality (that is, adjustment for linkage bias). Log-link regression models were used including only the eligible mortality records, with: the dependent variable being whether the mortality record was linked to a census record; and independent variables being age, ethnicity, rurality, socioeconomic deprivation (measured by a census derived index for small areas of about 100 people ${ }^{27}$ ), regional average income (quartiles) and regional income inequality (quartiles). The relative risks of linkage from these models were then used to adjust the observed odds ratios in the cohort analyses. For example, if the relative risk of linkage for deaths in the highest quartile of income inequality compared with the lowest quartile was 0.95 (that is, $5 \%$ less likely to be linked), and the observed odds ratio of death in the cohort analysis was 1.05 (that is, a 5\% observed excess mortality risk for people living in high income inequality areas), then the adjusted odds ratio was 1.05/ $0.95=1.11$. The third sensitivity analysis was to rerun the main logistic regression models with random intercepts for each region, using the SAS supplied macro Glimmix in SAS v8.0. (We choose not to routinely use random effects models for our analyses for two reasons. Firstly, random effects models arose from clustered survey sampling work (for example, children within classrooms within schools within areas-our analyses are for a complete cohort. Secondly, while there was probably some residual intraclass correlation on unmeasured variables within regions following control for covariates, the same could be said of all the independent variables. For example, even controlling for age and deprivation, there will be residual correlation of unmeasured factors (for example, income) with ethnicity. Thus, it seems inappropriate to just specify random intercepts for the regional variable.)

\section{RESULTS}

Table 1 shows the distribution of census respondents by the variables of interest.

\section{All cause mortality}

Controlling for age, ethnicity, rurality, and equivalised household income, the quartile odds ratios for income inequality and average income showed no association with all cause mortality (table 1). Modelling the Gini and average income as continuous variables (but with no other change to the model) the odds ratio of mortality for a 0.01 increase in the Gini was 1.007 (95\% confidence intervals 0.989 to 1.024 ) for men and 1.004 ( 0.983 to 1.026$)$ for women.

While we found no overall association of income inequality with all cause mortality, it was possible that the association of household income with mortality might be stronger in higher income inequality sub-regions ( that is, cross level effect modification). We divided the cohort into those living in high (top two quartiles) and low (bottom two quartiles) income inequality sub-regions. There was no difference in the association of household income with all cause mortality between these two sub-populations (results available from authors).

Figure 1 shows the odds ratio of all cause mortality for an increase in the Gini of 0.01 for models that include the Gini as a continuous variable. The first model includes just age and rurality as covariates, and sequential models introduce sub-region average income (also as a continuous variable), household income, and ethnicity. For both sexes there is an approximate $1 \%$ increase in mortality risk for a 0.01 increase in the Gini when controlling for only age and rurality (model $\mathrm{l}$ in fig 1). Additional control for average sub-region income (model 2) results in odds ratios of 1.021 (95\% confidence intervals 1.004 to 1.039 ) and 1.027 (1.006 to 1.049 ) for a 0.01 
Table 1 Odds ratios of all cause mortality by sub-region average household income and income inequality for 1.4 million New Zealand 1991 census respondents aged 25-64 years followed up for mortality for three years

\begin{tabular}{|c|c|c|c|c|c|c|c|c|}
\hline & \multicolumn{4}{|l|}{ Men } & \multicolumn{4}{|l|}{ Women } \\
\hline & Deaths & $\mathrm{n}$ & $\begin{array}{l}\text { Observed OR } \\
(95 \% \mathrm{Cl})\end{array}$ & $\begin{array}{l}\text { Linkage } \\
\text { adj OR }\end{array}$ & Deaths & $\mathrm{n}$ & $\begin{array}{l}\text { Observed OR } \\
(95 \% \text { CI) }\end{array}$ & $\begin{array}{l}\text { Linkage } \\
\text { adj OR }\end{array}$ \\
\hline \multicolumn{9}{|c|}{ Individual level variables } \\
\hline \multicolumn{9}{|l|}{ Ethnicity } \\
\hline Maori & 828 & 63207 & 1.93 (1.79 to 2.09 ) & 2.10 & 642 & 68346 & 2.32 (2.12 to 2.53$)$ & 2.59 \\
\hline Pacific & 153 & 21261 & 1.07 (0.91 to 1.27 ) & 1.30 & 93 & 22665 & 1.08 (0.87 to 1.33 ) & 1.61 \\
\hline Non-M non-P & 5241 & 604389 & 1 & 1.00 & 3342 & 611253 & 1 & 1.00 \\
\hline \multicolumn{9}{|c|}{ Equivalised household income } \\
\hline$<\$ 10000$ & 891 & 65004 & 2.15 (1.90 to 2.42 ) & & 666 & 94767 & 1.61 (1.38 to 1.88 ) & \\
\hline$\$ 10000-\$ 14999$ & 1302 & 89265 & 1.96 (1.75 to 2.20$)$ & & 990 & 108477 & 1.53 (1.32 to 1.77 ) & \\
\hline$\$ 15000-\$ 19999$ & 864 & 90276 & 1.68 (1.49 to 1.90$)$ & & 567 & 93285 & 1.36 (1.16 to 1.58$)$ & \\
\hline$\$ 20000-\$ 24999$ & 897 & 99243 & 1.55 (1.38 to 1.74$)$ & & 540 & 96729 & 1.25 (1.07 to 1.46$)$ & \\
\hline$\$ 25000-\$ 29999$ & 654 & 78960 & 1.51 (1.34 to 1.71$)$ & & 375 & 74670 & 1.23 (1.04 to 1.44$)$ & \\
\hline$\$ 30000-\$ 34999$ & 489 & 68658 & 1.29 (1.13 to 1.47$)$ & & 276 & 62889 & 1.05 (0.88 to 1.25$)$ & \\
\hline$\$ 35000-\$ 39999$ & 327 & 50793 & 1.14 (0.98 to 1.32 ) & & 210 & 46041 & 1.10 (0.91 to 1.32$)$ & \\
\hline$\$ 40000-\$ 49999$ & 378 & 66816 & 1.07 (0.93 to 1.23 ) & & 210 & 57666 & $0.95(0.79$ to 1.15$)$ & \\
\hline$\geqslant \$ 50000$ & 414 & 79845 & 1 & & 240 & 67737 & 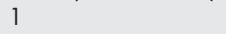 & \\
\hline \multicolumn{9}{|l|}{ Rural-urban } \\
\hline Urban & 4695 & 524451 & 1 & 1.00 & 3075 & 545145 & 1 & 1.00 \\
\hline Minor Urban & 696 & 54807 & $1.09(1.00$ to 1.18$)$ & 1.07 & 513 & 57363 & 1.24 (1.12 to 1.37$)$ & 1.14 \\
\hline Rural and Other & 828 & 109599 & 0.73 (0.67 to 0.79$)$ & 0.75 & 483 & 99753 & 0.80 (0.72 to 0.89 ) & 0.83 \\
\hline \multicolumn{9}{|c|}{ Sub-Region level variables } \\
\hline \multicolumn{9}{|c|}{ Quartile of average household income } \\
\hline Low & 792 & 73188 & $1.04(0.95$ to 1.15$)$ & 1.01 & 504 & 73110 & $1.02(0.91$ to 1.15$)$ & 1.03 \\
\hline Med-low & 1152 & 121230 & 0.94 (0.87 to 1.02$)$ & 0.92 & 789 & 123195 & 0.99 (0.89 to 1.09 ) & 0.98 \\
\hline Med-high & 1842 & 200175 & 1.01 (0.94 to 1.08 ) & 0.97 & 1230 & 203877 & 1.03 (0.95 to 1.12 ) & 1.01 \\
\hline High & 2436 & 294264 & 1 & 1.00 & 1554 & 302079 & 1 & 1.00 \\
\hline \multicolumn{9}{|c|}{ Quartile of income inequality } \\
\hline Low & 1128 & 121557 & 1 & 1.00 & 750 & 123147 & 1 & 1.00 \\
\hline Med-low & 1866 & 214641 & 0.97 (0.89 to 1.05$)$ & 0.97 & 1,275 & 219699 & 0.98 (0.88 to 1.09 ) & 1.00 \\
\hline Med-high & 1635 & 181134 & $1.02(0.94$ to 1.10$)$ & 1.02 & 1,005 & 185076 & 0.92 (0.83 to 1.02$)$ & 0.96 \\
\hline High & 1590 & 171528 & $1.01(0.93$ to 1.10$)$ & 1.02 & 1,044 & 174336 & $0.97(0.87$ to 1.07$)$ & 1.05 \\
\hline
\end{tabular}

increase in the Gini for men and women, respectively. This excess risk changes little after control for household income, but essentially disappears after control for ethnicity at the individual level with odds ratios becoming 1.007 (0.989 to 1.024 ) and 1.004 (0.983 to 1.026$)$, respectively.

\section{Sensitivity analyses for all cause mortality}

Using the model specification shown in table 1 there was little evidence of an association of income inequality with all cause mortality for both sexes at either the territorial authority or regional council levels (table 2 ). (Because of slight variation in geographical boundaries, 30417 census respondents that had

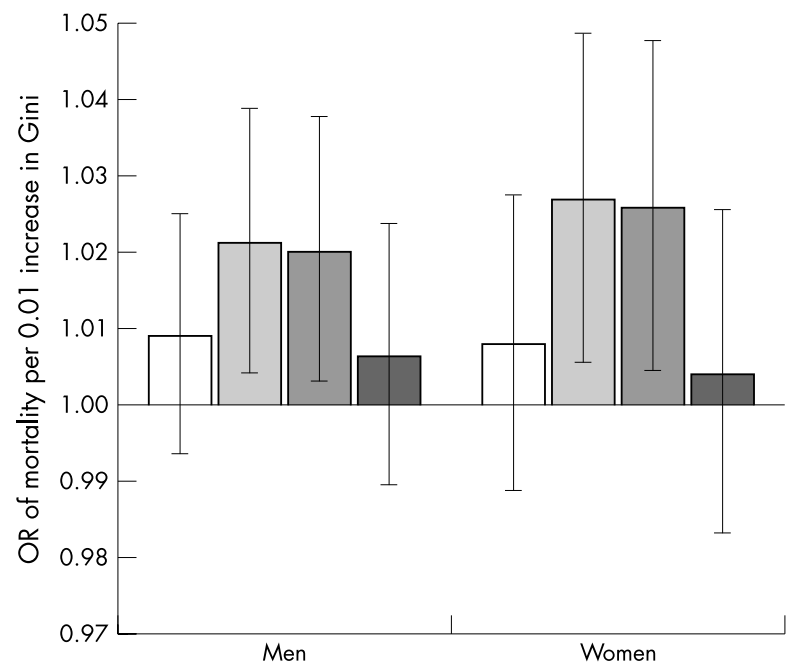

missing values for sub-region actually had a value for territorial authority and regional council.)

The two models shown in table 1 were repeated using random intercepts for each of the sub-regions. The quartile odds ratios were relatively unchanged and the confidence intervals increased in size by $50 \%$ to $60 \%$ (results available from authors).

Regarding possible linkage bias, female (but not male) deaths in higher income inequality sub-regions tended to be slightly less likely to be linked to a census record than deaths in the lowest quartile of income inequality (results available from authors). Adjusting for this modest linkage bias (as shown in the final column in table 1) did not substantially 
Table 2 Odds ratios of all cause mortality by income inequality measured at various regional levels for 1.4 million New Zealand 1991 census respondents aged 25-64 years followed up for mortality for three years

\begin{tabular}{|c|c|c|c|c|c|c|c|c|}
\hline \multirow{2}{*}{$\begin{array}{l}\text { Quartile of } \\
\text { income } \\
\text { inequality }\end{array}$} & \multicolumn{4}{|l|}{ Men } & \multicolumn{4}{|l|}{ Women } \\
\hline & Deaths & $\mathrm{n}$ & $\begin{array}{l}\text { Observed OR } \\
(95 \% \mathrm{CI})\end{array}$ & $\begin{array}{l}\text { Linkage } \\
\text { adj OR }\end{array}$ & Deaths & $\mathrm{n}$ & $\begin{array}{l}\text { Observed OR } \\
(95 \% \mathrm{CI})\end{array}$ & $\begin{array}{l}\text { Linkage } \\
\text { adj OR }\end{array}$ \\
\hline \multicolumn{9}{|c|}{ Regional council $(n=14)$} \\
\hline Low & 537 & 58182 & 1 & 1.00 & 390 & 59055 & 1 & 1.00 \\
\hline Med-low & 1884 & 199914 & 1.02 (0.92 to 1.14$)$ & 1.02 & 1170 & 201441 & $0.99(0.87$ to 1.13$)$ & 1.02 \\
\hline Med-high & 1326 & 137697 & $0.95(0.83$ to 1.08$)$ & 0.97 & 927 & 141042 & $1.09(0.93$ to 1.29$)$ & 1.14 \\
\hline High & 2616 & 308202 & $0.99(0.85$ to 1.15$)$ & 1.09 & 1668 & 315996 & 1.07 (0.89 to 1.29$)$ & 1.11 \\
\hline \multicolumn{9}{|c|}{ Sub-region $(n=35)$} \\
\hline Low & 1128 & 121557 & 1 & 1.00 & 750 & 123147 & 1 & 1.00 \\
\hline Med-low & 1866 & 214641 & $0.97(0.89$ to 1.05$)$ & 0.97 & 1275 & 219699 & $0.98(0.88$ to 1.09$)$ & 1.00 \\
\hline Med-high & 1635 & 181134 & $1.02(0.94$ to 1.10$)$ & 1.02 & 1005 & 185076 & $0.92(0.83$ to 1.02$)$ & 0.96 \\
\hline High & 1590 & 171528 & $1.01(0.93$ to 1.10$)$ & 1.02 & 1044 & 174336 & $0.97 \quad(0.87$ to 1.07$)$ & 1.05 \\
\hline \multicolumn{9}{|c|}{ Territorial authority $(n=73)$} \\
\hline Low & 1080 & 119391 & 1 & 1.00 & 708 & 120510 & 1 & 1.00 \\
\hline Med-low & 2211 & 248469 & 1.01 (0.93 to 1.09 ) & 1.00 & 1473 & 256836 & 1.02 (0.93 to 1.12$)$ & 1.05 \\
\hline Med-high & 1800 & 195093 & 1.08 (0.99 to 1.17$)$ & 1.08 & 1131 & 198189 & $1.01(0.91$ to 1.11$)$ & 1.03 \\
\hline High & 1272 & 141048 & 1.04 (0.95 to 1.13$)$ & 1.07 & 843 & 141996 & $1.02(0.92$ to 1.13$)$ & 1.10 \\
\hline
\end{tabular}

change the findings. Likewise, there was no substantial impact of adjusting regional council and territorial authority analyses for linkage bias (final column for each sex in table 2).

\section{Cause specific mortality}

Table 3 shows the income inequality odds ratios for cancer, cardiovascular disease, unintentional injury, and suicide deaths. The findings were null for all male causes of death and null for female cardiovascular deaths. Regarding women, the quartile odds ratio suggested some positive association for injury and suicide deaths and (possibly) some negative association for cancer deaths. However, these latter findings were based on comparatively few deaths and much of the apparent association might have been attributable to comparatively low mortality in the reference category. Notably, the 95\% confidence intervals for all the continuous Gini odds ratios in table 3 included 1.0. Adjusting the cause specific results for linkage bias had no notable impact on the results other than perhaps strengthening the suggestion of a null finding for female cancer deaths (table 3 ).

Table 3 Odds ratios of cause specific mortality by sub-region income inequality for 1.4 million New Zealand 1991 census respondents aged 25-64 years followed up for mortality for three years

\begin{tabular}{|c|c|c|c|c|c|c|}
\hline \multirow{2}{*}{$\begin{array}{l}\text { Income inequality } \\
\text { (either quartiles or } \\
\text { per } 0.01 \text { Change in } \\
\text { continuous Gini) }\end{array}$} & \multicolumn{3}{|l|}{ Men } & \multicolumn{3}{|l|}{ Women } \\
\hline & Deaths & $\begin{array}{l}\text { Observed OR } \\
(95 \% \mathrm{Cl})\end{array}$ & $\begin{array}{l}\text { Linkage } \\
\text { adj OR }\end{array}$ & Deaths & $\begin{array}{l}\text { Observed OR } \\
(95 \% \mathrm{CI})\end{array}$ & $\begin{array}{l}\text { Linkage } \\
\text { adj OR }\end{array}$ \\
\hline \multicolumn{7}{|l|}{ Cancer, quartiles } \\
\hline Low & 369 & 1 & 1 & 408 & 1 & 1 \\
\hline Med-low & 675 & 1.07 (0.93 to 1.24 ) & 1.11 & 696 & $0.94(0.81$ to 1.08$)$ & 0.96 \\
\hline Med-high & 558 & $1.10(0.96$ to 1.27$)$ & 1.15 & 516 & 0.86 (0.75 to 0.99 ) & 0.89 \\
\hline High & 546 & $1.11(0.96$ to 1.28$)$ & 1.13 & 498 & 0.86 (0.74 to 0.99 ) & 0.95 \\
\hline \multirow{2}{*}{\multicolumn{7}{|c|}{$\begin{array}{l}\text { Cancer, continuous Gini } \\
0.01 \text { increase in Gini }\end{array}$}} \\
\hline & & 1.007 (0.979 to 1.037 ) & & & 0.981 (0.952 to 1.011$)$ & \\
\hline \multicolumn{7}{|l|}{ CVD, quartile } \\
\hline Low & 483 & 1 & 1 & 192 & 1 & 1 \\
\hline Med-low & 732 & $0.91(0.80$ to 1.04$)$ & 0.91 & 282 & 0.90 (0.73 to 1.11$)$ & 0.94 \\
\hline Med-high & 648 & $0.92(0.81$ to 1.04$)$ & 0.90 & 246 & 0.84 (0.69 to 1.03 ) & 0.92 \\
\hline High & 636 & $0.92(0.81$ to 1.05$)$ & 0.93 & 285 & 0.94 (0.77 to 1.16 ) & 1.01 \\
\hline \multirow{2}{*}{\multicolumn{7}{|c|}{$\begin{array}{l}C V D \text {, continuous Gini } \\
0.01 \text { increase in Gini }\end{array}$}} \\
\hline & & 0.998 (0.972 to 1.026$)$ & & & 1.029 (0.986 to 1.073 ) & \\
\hline \multicolumn{7}{|l|}{ Injury } \\
\hline Low & 69 & 1 & 1 & 21 & 1 & 1 \\
\hline Med-low & 114 & $1.03(0.73$ to 1.46$)$ & 1.05 & 45 & $1.46(0.81$ to 2.62$)$ & 1.44 \\
\hline Med-high & 117 & $1.29(0.94$ to 1.78$)$ & 1.35 & 45 & 1.98 (1.15 to 3.40$)$ & 1.96 \\
\hline High & 93 & $0.99(0.70$ to 1.38$)$ & 1.13 & 36 & $1.63(0.91$ to 2.92$)$ & 1.69 \\
\hline \multicolumn{7}{|l|}{ Injury, continuous Gini } \\
\hline 0.01 increase in Gini & & 0.958 (0.892 to 1.030$)$ & & & 1.068 (0.952 to 1.198$)$ & \\
\hline \multicolumn{7}{|l|}{ Suicide } \\
\hline Low & 63 & 1 & 1 & 15 & 1 & 1 \\
\hline Med-low & 87 & 0.77 (0.53 to 1.12$)$ & 0.86 & 33 & $1.70(0.82$ to 3.53$)$ & 1.68 \\
\hline Med-high & 66 & 0.79 (0.54 to 1.13$)$ & 0.90 & 21 & 1.41 (0.69 to 2.88 ) & 1.40 \\
\hline High & 78 & 0.97 (0.67 to 1.40 ) & 0.98 & 27 & 1.97 (0.96 to 4.02 ) & 1.97 \\
\hline \multirow{2}{*}{$\begin{array}{l}\text { Suicide, continuous Gini } \\
0.01 \text { increase in Gini }\end{array}$} & & & & & & \\
\hline & & 1.021 (0.945 to 1.102$)$ & & & 1.087 (0.957 to 1.234$)$ & \\
\hline
\end{tabular}




\section{DISCUSSION}

We found no convincing association of income inequality with all cause mortality within New Zealand. A previous New Zealand ecological study of income inequality and all cause mortality by the same sub-region regions used in our multi-level study found some association in the expected direction. ${ }^{17}$ Based on the results presented in figure 1 it seems this previous ecological finding was attributable to confounding by the varying ethnic group composition of regions in New Zealand. Maori and Pacific people tend to have lower incomes than non-Maori ${ }^{28}$ and higher mortality rates, ${ }^{29-31}$ meaning that regions with high proportions of Maori and Pacific people will have higher mortality rates. In parallel, as Maori and Pacific people are minority ethnic groups overall in New Zealand, regions with higher proportions of Maori and Pacific people will tend to have a more dispersed range of incomes resulting in higher income inequality. Consequently, ecological analyses that do not adjust for ethnicity will observe a spurious association of income inequality and mortality due to (uncontrolled) confounding for ethnicity at the individual level. Indeed, repeating the previously published age and sex standardised ecological analyses, ${ }^{17}$ but additionally standardised for ethnicity, removes the association of regional income inequality with mortality consistent with the analyses in this paper (results available on request from $\mathrm{O}^{\prime} \mathrm{Dea}$ ).

Could controlling for ethnicity at the individual level be a form of over-control? For this to be the case either people modify their self identified ethnicity consequent on regional income inequality, or Maori (non-Maori) tend to migrate to (out of) high income inequality regions. We believe these two possibilities are implausible. Instead, confounding by ethnicity at the individual level of the crude association of income inequality with mortality is the most probable explanation. Our study reinforces the importance of ethnic inequalities in health in New Zealand. In this context, these ethnic inequalities also give rise to important regional inequalities in health. There are good reasons why we might not expect an association of income inequality with adult mortality within New Zealand. Firstly, New Zealand has comparatively little regional variation in education, health, welfare and other systems that might plausibly explain any neo-material basis to the association of income inequality with health. ${ }^{21}{ }^{32}$ Secondly, and related to the first reason, there is probably less variation in income inequality by region than in other countries because of the same taxation and government systems applying throughout in New Zealand. While it is difficult to make comparisons of income inequality between countries it seems likely that both the range of income inequality (the exposure) within New Zealand is narrower than for US counties and metropolitan areas and the level of regional income inequality is less. ${ }^{14}$ These two reasons may also be possible explanations for the lack of association of regional income inequality with mortality in Canada. ${ }^{18}$

It is possible that our null study may unduly dismiss the association within New Zealand. For cardiovascular disease and tobacco related cancers it would take time for any contextual effect of income inequality to influence risk behaviours and (patho)physiology..$^{33}$ Future analyses in New Zealand should examine the possibility of time lags by modelling income inequality measures some time before death. Also, given the large increase in income inequality in New Zealand in the late 1980s, following up mortality in the late 1990s and beyond based on early 1990s income inequality measures seems sensible. However, elsewhere we have found that investigating income inequality time lags is difficult because of relative stability of regional rankings by income inequality over time and individual mobility over time between regions. Of note, if psychosocial mechanisms underlie any association of income inequality with health, then one might still expect to see an association of income inequality with suicide (plus or

\section{Key points}

- Income inequality is associated with health outcomes within the US at the state level although the causal significance of this association is debated.

- Within other countries, the evidence of any association of regional income inequality with health is mixed.

- This study finds no convincing association of income inequality with all cause or cause specific mortality within New Zealand.

- Previous ecological analyses in New Zealand that found an association of income inequality with mortality were confounded by ethnicity.

- The association of income inequality with health in the US does not seem to be generalisable to other countries.

minus injury) in our study-there was possible evidence of this for women, but it was not statistically significant.

Our study does not provide evidence against the possible importance of income inequality at the country level. For example, New Zealand has experienced a rapid increase in income and other inequalities in the past 20 years. It is, however, a moot point whether this has been detrimental to the overall health status of New Zealanders.

Our findings, and other recently published studies, ${ }^{19} 2034$ suggest that the study of the association of income inequality with health within other countries should be approached cautiously. Firstly, any apparent association from ecological analysis may be attributable to individual level confounding, and not necessarily just by individual level income as might be expected mathematically. ${ }^{35}$ In our study ethnicity was confounding the association of income inequality with mortality. Secondly, there are many limitations to using within country analyses to test the income inequality hypothesis including unmeasured confounding by region, inadequate allowance for time lags, and inadequate variation of income inequality by regions within countries. ${ }^{336}$ Regarding the association of income inequality with health at the state level in the US, while it often remains after controlling for individual level confounding, ${ }^{91}{ }^{113}$ it does not seem to be generalisable to regional analyses within other countries. This lack of generalisability may either be because the US association is spurious because of ecological level confounding, ${ }^{37}$ or because the US has both large enough within country variation of income inequality and high enough levels of income inequality for the association to be observable. ${ }^{18}$

\section{ACKNOWLEDGEMENTS}

The NZCMS is conducted in collaboration with Statistics New Zealand and within the confines of the Statistics Act 1975. Comments on drafts of this paper were received from Philippa Howden-Chapman, Ichiro Kawachi, John Lynch, and Bruce Kennedy.

\section{Contributors}

Tony Blakely is the principal investigator of the NZCMS and is the guarantor of this study. He conceived of the paper, and led the design, interpretation and preparation of drafts of the paper. June Atkinson led the analyses, and contributed to the interpretation of results and revision of drafts. Des O'Dea contributed to the design, interpretation and revision of drafts.

\section{Summary Statistics New Zealand security statement}

(The full security statement is available at http://www.wnmeds.ac.nz/ nzcms-info.html). The New Zealand Census Mortality Study (NZCMS) is a study of the relation between socioeconomic factors and mortality in New Zealand, based on the integration of anonymised population census data from Statistics New Zealand and mortality data from the New Zealand Health Information Service. The project was approved by Statistics New Zealand as a Data Laboratory project under the Microdata Access Protocols in 1997. The datasets created by the integration process are covered by the Statistics Act and can be 
used for statistical purposes only. Only approved researchers who have signed Statistics New Zealand's declaration of secrecy can access the integrated data in the Data Laboratory. For further information about confidentiality matters in regard to this study please contact Statistics New Zealand.

\section{Authors' affiliations}

T Blakely, J Atkinson, D O'Dea, Department of Public Health, Wellington School of Medicine, University of Otago, Wellington, New Zealand

\section{Conflicts of interest: none.}

Funding: The New Zealand census-mortality study (NZCMS) is funded by the Health Research Council of New Zealand, with co-funding from the New Zealand Ministry of Health.

\section{REFERENCES}

1 Rodgers GB. Income and inequality as determinants of mortality: an international cross-section analysis. Population Studies 1979;33:343-51.

2 Hales S, Howden-Chapman P, Salmond C, et al. National infant mortality rates in relation to gross national product and distribution of income. Lancet 1999;354:2047.

3 Lynch J, Davey Smith G, Hillemeier M, et al. Income inequality, the psychosocial environment and health: comparisons of wealthy nations. Lancet 2001;358:194-200.

4 Wilkinson R. Income distribution and life expectancy. BM 1992;304:165-8.

5 Kennedy B, Kawachi I, Prothrow-Stith D. Income distribution and mortality: cross sectional ecological study of the Robin Hood index in the United States. BM 1996;312:1004-7.

6 Kaplan G, Pamuk E, Lynch J, et al. Inequality in income and mortality in the United States: analysis of mortality and potential pathways. BM 1996;312:999-1003.

7 Lynch J, Kaplan G, Pamuk E, et al. Income inequality and mortality in metropolitan areas of the United States. Am J Public Health 1998:88:1074-80.

8 Brodish P, Massing M, Tyroler $\mathrm{H}$. Income inequality and all-cause mortality in the 100 countries of North Carolina. South Med J 2000;93:386-91.

9 Kennedy B, Kawachi I, Glass R, et al. Income distribution, socioeconomic status, and self-rated health in the United States: multilevel analysis. BM 1998;317:917-21.

10 Blakely T, Kennedy B, Kawachi I. Socio-economic inequality in voting participation and self-rated health. Am J Public Health 2001;91:99-104.

11 Lochner K, Pamuk E, Makuc D, et al. State-level income inequality and individual mortality risk: a prospective, multi-level study. Am J Public Health 2001;91:385-91.

12 Daly M, Duncan G, Kaplan G, et al. Macro-to-micro links in the relation between income inequality and mortality. Milbank Q 1998;76:315-39.

13 Soobader M-J, LeClere F. Aggregation and the measurement of income inequality: effects on morbidity. Soc Sci Med 1999;48:733-44.

14 Blakely T, Lochner K, Kawachi I. Metropolitan area income inequality and self-rated health: a multi-level study. Soc Sci Med 2002;54:65-77.

15 Fiscella K, Franks P. Poverty or income inequality as predictor of mortality: longitudinal cohort study. BM 1997;314:1724-8.

16 Stanistreet D, Scott-Samuel A, Bellis M. Income inequality and mortality in England. J Public Health Med 1999;21:205-7.
17 O'Dea D, Howden-Chapman P. Income and Income Inequality and Health. In: Howden-Chapman P, Tobias $M$, eds. Social inequalities in health in New Zealand: New Zealand 1999. Wellington, NZ: Ministry of Health, 2000.

18 Ross N, Wolfson M, Dunn J, et al. Relation between income inequality and mortality in Canada and in the United States: cross sectional assessment using census data and vital statistics. BM 2000;320:898902.

19 Shibuya K, Hashimoto H, Yano E. Individual income, income distribution, and self rated health in Japan: cross secitonal analyses of nationally representative sample. BM 2002;324:16-19.

20 Osler $M$, Prescott E, Gronbaek $M$, et al. Income inequality, individual income, and mortality in Danish adults: analysis of pooled data from two cohort studies. BM 2002;324:13-16.

21 Kawachi I, Kennedy B. Income inequality and health: pathways and mechanisms. Health Serv Res 1999;34:215-27.

22 Lynch J, Davey Smith G, Kaplan G. Income inequality and mortality: importance to health of individual income, psychosocial environment, or material conditions. BM 2000;320:1200-4.

23 Backlund E, Sorlie PD, Johnson NJ. The shape of the relationship between income and mortality in the United States: evidence from the National Longitudinal Mortality Study. Ann Epidemiol 1996;6:12-20.

24 Blakely T, Salmond C, Woodward A. Anonymous record linkage of 1991 census records and 1991-94 mortality records: The New Zealand Census-Mortality Study. Wellington: Department of Public Health, Wellington School of Medicine, University of Otago, 1999 (http://www.wnmeds.ac.nz/nzcms-info.html).

25 Blakely T, Salmond C, Woodward A. Anonymous linkage of New Zealand mortality and Census data. Aust NZ J Public Health 2000;24:92-5.

26 Blakely T. The New Zealand Census-Mortality Study: socioeconomic inequalities and adult mortality 1991-94. Wellington: Ministry of Health 2002:258 (http://www.wnmeds.ac.nz/nzcms-info.html).

27 Salmond C, Crampton P, Sutton F. NZDep91: A New Zealand index of deprivation. Aust NZ J Public Health 1998;22:835-7.

28 Statistics New Zealand. New Zealand now: incomes. Wellington: Statistics New Zealand, 1999.

29 Pomare E, Keefe-Ormsby V, Ormsby C, et al. Havora: Maori standards of health III. Wellington: Eru Pomare Maori Health Research Centre, 1995.

30 Howden-Chapman $\mathbf{P}$, Tobias $M$, eds. Social inequalities in Health: New Zealand 1999. Wellington, NZ: Ministry of Health, 2000.

31 Blakely T, Kiro C, Woodward A. Unlocking the numerator-denominator bias. Il: adjustments to mortality rates by ethnicity and deprivation during 1991-94. NZ Med J 2002;115:43-8.

32 Lynch J. Income inequality and health: expanding the debate. Soc Sci Med 2000;51:1001-5.

33 Blakely T, Kennedy B, Glass R, et al. What is the lag time between income inequality and heath status? J Epidemiol Community Health 2000;54:318-19.

34 Sturm R, Gresenev C. Relations of income inequality and family income to chronic medical conditions and mental health disorders: national survey. BM 2002;324:20-3

35 Gravelle $\mathbf{H}$. How much of the relation between population mortality and unequal distribution of income is a statistical artefact? BM 1998;316:382-5

36 Blakely T, Woodward A. Ecological effects in multi-level studies. $J$ Epidemiol Community Health 2000;54:367-74

37 Blakely T, Woodward A. Third explanation is plausible. [Letter]. BM 2000;321:1532. 